\title{
EFICÁCIA DE HERBICIDAS NO CONTROLE DE AMARELINHO (Tecoma stans) EM PASTAGEM ${ }^{1}$
}

TELMA PASSINI $^{2}$ e WALTER MIGUEL KRANZ ${ }^{2}$

\section{RESUMO}

Amarelinho (Tecoma stans) é um arbusto exótico que foi observado como espécie invasora de pastos degradados do Estado do Paraná Brasil. A população dessa espécie forma um dossel denso sob o qual as forrageiras não se desenvolve $\mathrm{m}$. Visando encontrar uma alternativa de controle químico, testou-se a eficiência da formulação comercial de 2,4-D + picloram e tebuthiuron, em experimentos separados. Com a formulação comercial de 2,4-D + picloram preparou-se uma solução em água e em óleo lubrificante usado, nas concentrações de $4 \%$ e $10 \%$. As soluções a $4 \%$ foram pinceladas no toco, imediatamente após o tronco ter sido cortado rente ao solo e, aquelas a $10 \%$, pinceladas em tronco ferido com facão na base do tronco, sem eliminar a parte aé rea. Te buthiuron, em formul ação granulada, foi aplicado nas doses de $2,4,6,8,10$ e $20 \mathrm{~g} / \mathrm{planta}$, sem eliminar a parte aérea. A for mulação de 2,4-D + picloram não matou as plantas de amarelinho que, aos cinco meses após tratadas, apresentavam brotações com 0,74 a $1,21 \mathrm{~m}$ de altura. A me nor do se de tebuthiuron foi suficiente para matar as plantas num período de nove meses após a aplicação do herbicida.

Palavras chave: Stenolobium stans, ipêmirim, 2,4-D, picloram, tebuthiuron.

\section{ABSTRACT \\ Herbicides efficiency on trumpetflower (Tecoma stans)}

Trumpetflower (Tecoma stans) is an exotic woody shrub observed as an invader of degraded pastures in the State of Parana - Brazil. The canopy of trumpetflower is so dense that no forage plants grow underneath. The chemical control of this weed was tested in two experiments, using the commercial formulation of 2,4-D + picloram and tebuthiuron. The former was prepare d as a solution into water or lubricative used oil, at the concentrations of 4 and $10 \%$. The solutions at $4 \%$ were used for painting the stumps immediatly after trunks had being cut off, close to the ground level. The solutions at $10 \%$ were used for painting the basal portion of the trunks, immediatly after damaging it with a machete close to the ground level. Tebuthiuron was used granulated at doses of 2, 4, 6, 8, 10 e $20 \mathrm{~g} /$ plant. The doses were dressed on the soil near the base of the trunk. The formulation 2,4-D + picloram did not kill the plants, which produced new shoots 0,74 to $1,21 \mathrm{~m}$ high five month after the treatment. Tebuthiuron was effective even at the lowest dose of $2 \mathrm{~g} /$ plant. After the treatment, plant died in nine months.

Key words: Stenolobium stans, 2,4-D, picloram, tebuthiuron, pasture.

'1Recebido para publicação em 19/09/96 e na forma revisada em 24/10/97.

2Eng ${ }^{\circ}$ Agr, MSc, Pesquisadores do Instituto Agronômico do Paraná-TAPAR. Caixa Postal 481, CEP 86001-970, Londrina-PR. 


\section{INTRODUÇÃO}

Ipê-de-jardim, ipê-mirim, guarã-guarã e caroba amarela são alguns dos nomes pelos quais é vulgarmente conhecida a espécie Tecoma stans (L.) Kunth. No Paraná é mais conhecida como amarelinho.

A espécie é nativa do México e sul dos Estados Unidos, mais precisamente, sul do Texas, Arizona e Novo México (Morton, 1981). Segundo o autor, é cultivada como ornamental na América Central, América do Sul, Caribe, Bahamas, região sul da Flórida e áreas quentes do mundo antigo. $\mathrm{Na}$ Argentina, Nicarágua e Estados Unidos, foi mencionada como planta daninha (Holm et al., 1979).

No Brasil, foi descrita como um dos melhores ele mentos de ornamentação para os jardins, para todas as regiões do país, exceto onde ocorram geadas muito severas (Blossfeld, 1965). Em Santa Catarina, foi encontrada na forma subespontânea em terrenos baldios e proximidades de habitações (Sandwith \& Hunt, 1974). Nc Paraná, a espécie foi observada em 167 dos seus 370 municípios; em 84 deles ocorre comc ornamental; em 73, como espontânea nas áreas urbanas; em 121, ao longo das rodovias e, em 85, em pastagens (Kranz \& Passini, 1996). Os municípios que apresentam áreas com maior infestação são Apucarana, Assai, Congonhinhas, Corbélia, Cornélio Procópio, Ibiporã, Kaloré, Londrina, Nova América da Colina, Nova Fátima. Novo Itacolomi, Ribeirão do Pinhal, Rio Bom. Santa Amélia e Sertanópolis.

Há vários anos, o IAPAR tem recebidc amostras de plantas de amarelinho pari identificação, procedentes de diversas regiões dc Paraná. As amostras, frequentemente, têm sidc acompanhadas de relato do insucesso do controle químico.

A espécie caracteriza-se por apresentai rebrota rápida e vigorosa após o corte do tronco por emitir brotações a partir de raízes grossas próximas do tronco, o que dificulta o seu controle através de métodos exclusivamente mecânicos.

$\mathrm{Na}$ bibliografia nacional não se localizou qualquer infor ma ção sobre o controle de amarel inho e, na internacional, apenas uma referência foi localizada num período de 24 anos, de autoria de Oakes (1970). Neste trabalho, o amarelinho não foi controlado por pulverizações foliares. Os herbicidas foram aplicados em dose única, duas aplicações, com um intervalo de nove meses entre uma e outra e três aplicações, com um intervalo de seis meses entre a primeira e a segunda e de sete meses entre a segunda e a terceira. Os herbicidas utilizados foram 2,4-D e 2,4,5-T, aplicados isoladamente ou em mistura, em solução aquosa ou em mistura de água + óleo diesel ou óleo + querosene e uma formulação de 2,4,5-T + MCP A, em água. Houve suc ess o no controle da espécie apenas no tratamento onde se realizou uma única pulverização basal de 2,4-D + 2,4,5-T a 0,33 + 0,5\% v/v, em óleo diesel.

Diante da dificuldade do controle mecânico, dos depoimentos de ineficiência do controle químico e da falta de informações na bibliografia, propôs-se o estudo da eficiência de 2,4-D + picloram e de tebuthi uron, com o intuito de encontrar opções para o controle de amarelinho.

\section{MATERIAL E MÉTODOS}

\section{Eficácia de 2,4-D + picloram'}

Um teste preliminar foi instalado em 12/12/94, em área de pinhão manso infestada com amarelinho (Tecoma stans), na estação experimental do Instituto Agronômico do Paraná, em Londrina.

As plantas de amarelinho, oriundas de rebrota, apresentavam um ou dois caules com até 0,05 m de diâme tro e altura esti mada em 3,0 m. Com a formulação comercial de 2,4-D + picloram foram preparadas duas soluções na concentração 
de $4 \%$, uma em água e outra em óleo lubrificante us ado e duas na de $10 \%$, usando os mesmos veículos. As soluções a $4 \%$ foram pinceladas no toco, imediatamente após o tronco ter sido cortado rente ao solo e, aquelas a $10 \%$, pinceladas em tronco ferido com facão, à volta toda do tronco, sem eliminar a parte aérea, numa altura aproximada de $0,10 \mathrm{~m}$ do solo.

\section{Tordon 2,4-D.}

Cada solução foi aplicada em cinco plantas, cada planta representando uma amostra.

A eficiência das soluções aplicadas por pincelamento no toco, foi avaliada quanto a porcentagem de plantas que rebrotaram, o número de rebrotas por planta e a altura média das rebrotas e, a eficiência das aplicadas por pincelamento no ferimento, sem eliminação da copa, foi avaliada quanto a porcentagem de plantas com desfolha, porcentage m de desfolha das plantas e porcentage m de plantas que apresentaram brotações. Essas avaliações foram realizadas aos 15, 30, 62 e 156 dias após o pincelamento.

Exceto a porcentagem de desfolha da planta que foi estimada visualmente, as demais variáveis, expressas em porcentagem, foram calculadas a partir de contagem.

\section{Eficácia de tebuthiuron2}

O experimento foi instalado em 14/06/95, em Ibi porã-PR, em área de pasto degradado, ocupado por grama mato-gros so. Selecionou-se uma população de amarelinho que havia sido roçada no ano anterior. Os tocos apresentavam três a seis rebrotas, as quais tinham altura estimada entre 2,0 e 3,0 m e diâmetro do caule estimado entre 0,02 e $0,04 \mathrm{~m}$. Todas as rebrotas estavam em fase vegetativa e bem enfolhadas.

\section{GrasIan 100 peletizado.}

Tebuthiuron, em formulação peletizada, foi testado nas doses de 2, 4, 6, 8, 10 e $20 \mathrm{~g}$ do ingrediente ativo por planta. Cada dose foi apl ica da em dez plantas, di stribuindo -se manualmente os peletes do produto ao redor da base do caule. O solo da área é de textura média e encontrava-se seco na data da aplicação.

A descrição dos sintomas foi realizada aos $28,50,93,135,186,240$ e 271 dias após a aplicação (DAA) do produto. Uma avaliação visual da porcentagem de desfolha das plantas foi feita 50 dias após o tratamento e uma contagem do número de plantas com brotações foi feita aos 240 dias após o tratamento. A de scrição dos sintomas e a avaliação visual da porcentagem de desfolha foram feitas pelo aspecto geral das 10 plantas tratadas com a mesma dose.

\section{RESULTADOS E DISCUSSÃO}

\section{Eficácia de 2,4-D + picloram.}

Nas plantas tratadas no toco, o uso de óleo como veículo, quando comparado ao da água, atrasou o início da rebrota (Figura 1) e a emissão de brotos até 62 dias após a aplicação do herbicida (Figura 2). As diferenças no número de brotações a partir da base do caule (Figurá 2) e na altura das mesmas (Fig ura 3), entre os do is veículos, evidenciam que as brotações das plantas tratadas com a solução em óleo tiveram seu crescimento retard ado em relação às tra tadas com sol ução aquosa. 


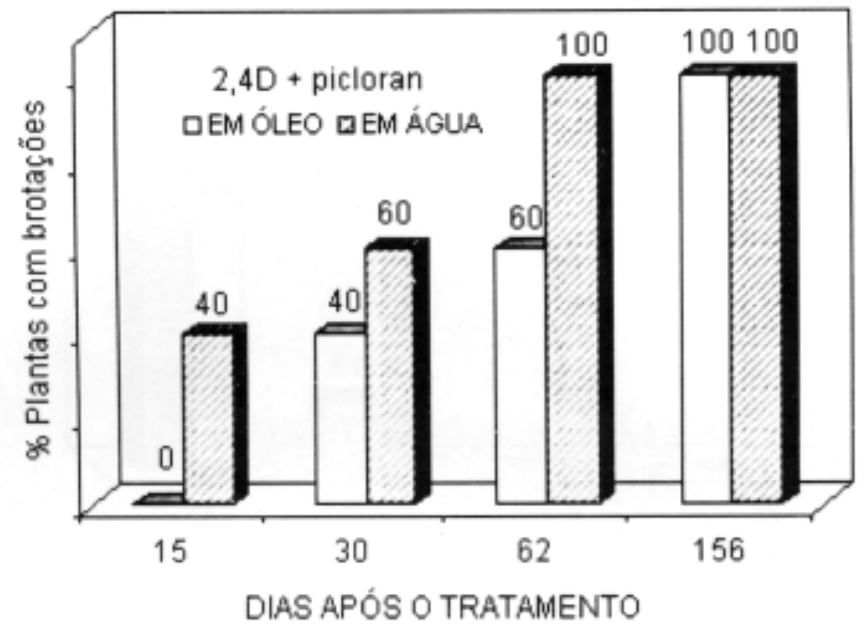

FIGU RA 1. Porce ntage m de plantas com brotações, após tratadas no toco. Média de cinco plant as. Londrina, 1994/95.

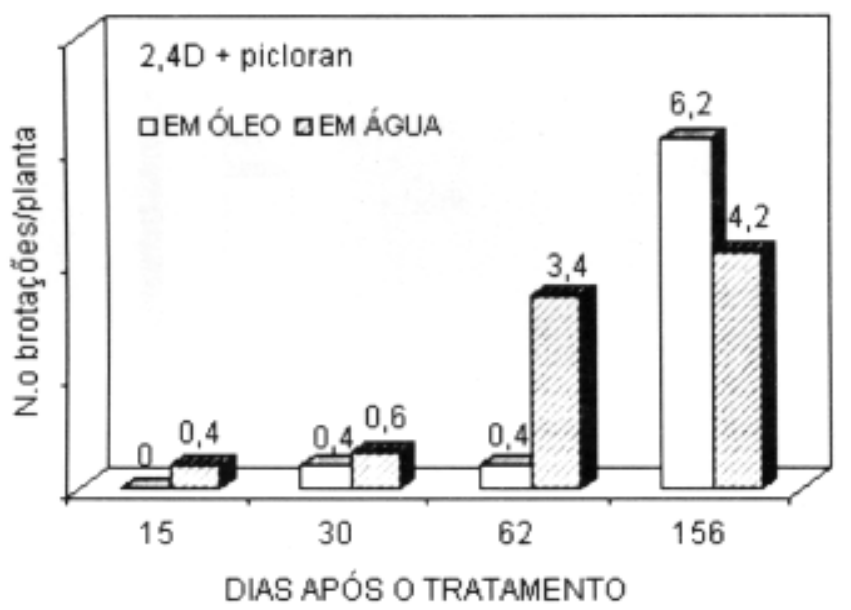

FIGURA 2. Número de brotações por planta, após tratadas no toco. Média de cinco plantas. Londrina, $1994 / 95$.

$\mathrm{O}$ efeito das soluções aplicadas sem a el iminação da copa foi mais lento. Não se obse rvou qual quer alteração nas plantas até 62 dias após a aplicação. Aos 156 dias, observou-se desfolha e brotações na base do tronco (Figura 4). Embora o efeito tenha sido mais acentuado com a solução em óleo, até aquela data, não havia desfolha total das plantas e, a porcentagem de plantas com brotações a partir do colo era de $60 \%$.

Como es sas formas de ap licação do produto não se mostraram promissoras, passou-se a estudar a possibilidade de uso de tebuthiuron, na modalidade de aplicação em acordo com sua formulação. 


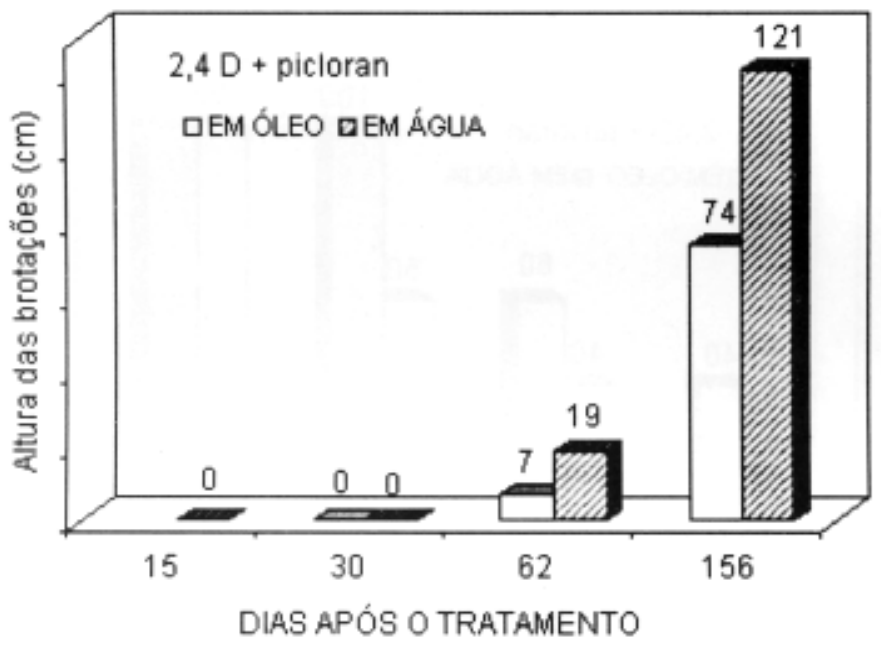

FIGURA 3. Altura média (cm) das brotações de cinco plantas, após tratadas no toco. Londrina, 1994/95.

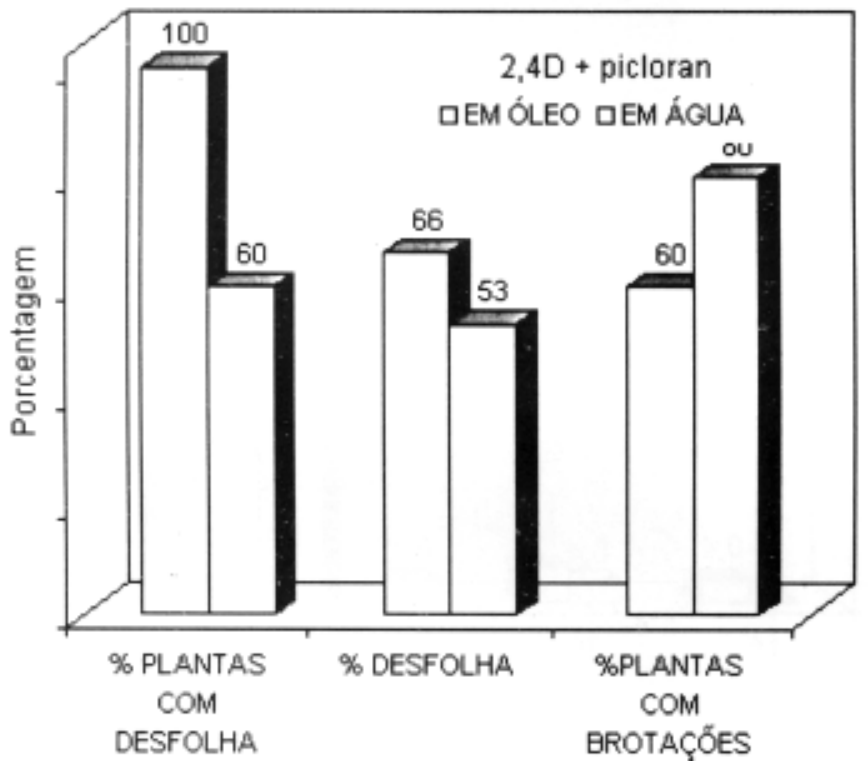

FIGURA 4. Efeito dos tratamentos realizados no tronco ferido, sem eliminação da copa. Média de cinco plantas. Londrina, 1994/95.

\section{Eficácia de tebuthiuron.}

Até 28 DAA, em quaisquer das doses utilizadas, não havia fitotoxicid ade visível. Como a aplicação foi realizada em solo seco e os peletes do produto comercial só liberam o herbicida com umidade (Rodrigues \& Almeida, 1995), a ausência de sintomas tóxicos até aquela data é justificada porque a oc or rência da maior precipitação pluviométrica (54 mm) ocorreu aos 26 dias após a aplicação (Figura 5). 


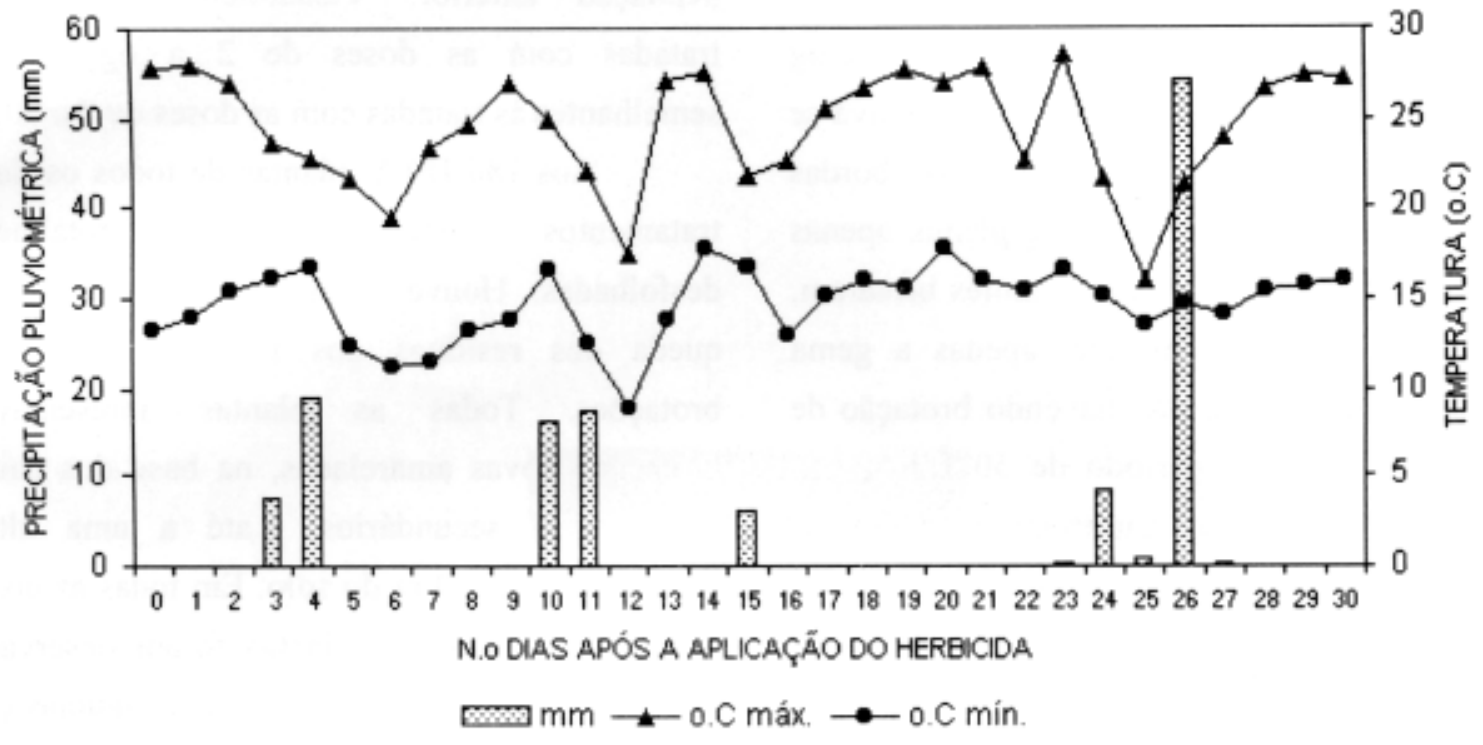

FIG URA 5. Precipitação plu viométric a $(\mathrm{mm})$ e tempera tura $\left({ }^{0} \mathrm{C}\right)$, nos promeiros trinta dias após a aplicação de tebuthiuron. Ibiporã, 1995.

Fonte: Estação Agrometeorológica do IAPAR, em Ibiporã.

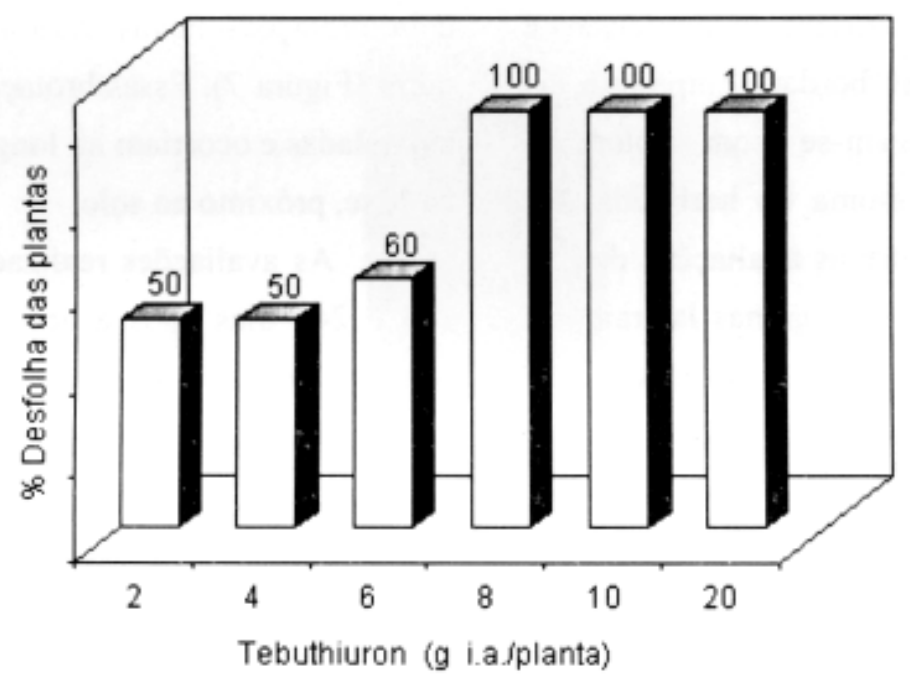

FIGURA 6. Porcentagem de desfolha das plantas, 50 dias após a aplicação de tebuthiuron. Média de 10 plantas. Ibiporã, 1995.

Aos 50 DAA, a desfolha das plantas variou entre 50 e $100 \%$ conforme a dose do produto (Figura 6). Nas plantas tratadas com $2 \mathrm{e}$
$4 \mathrm{~g}$ houve brotação das gemas laterais nos caules primários e secundários. Nas plantas tratadas com $6 \mathrm{~g}$, as gemas laterais dos caules primários e 
secundários ficaram apenas entumecidas ou em estádio inicial de brotação. Nas doses de 2, 4 e $6 \mathrm{~g}$ as folhas remanescentes apresentava-se amareladas e muitas delas, com as bordas necrosadas. Nas doses de 8 e 10 g/planta, apenas as gemas próximas ao ápice dos caules brotaram. Nas plantas tratadas com $20 \mathrm{~g}$, apenas a gema apical se desenvolveu, não havendo brotação de gemas laterais. Até o período de $50 \mathrm{DAA}$, não houve morte do ápice dos caules em nenhuma das doses.

Aos 93 DAA, em todas as doses, a desfolha das plantas foi total. Nessa data, observou-se uma grande quantidade de frutos verdes, em estádio de crescimento inicial a completo. Nas plantas tratadas com 2, 4 e 6g, as folhas mais velhas das brotações da gema apical e das ge mas laterais dos caules primários e secundários estavam descoloridas ou amareladas e algumas com necrose nas bordas. Entretanto, as folhas novas apresentavam-se com coloração normal, sem qualquer sintoma do herbicida. No período compreendido entre as avaliações dos 50 e 93 DAA, houve brotação de gemas laterais nas plantas tratadas com 8,10 e $20 \mathrm{~g}$, mas a quantidade de brotações foi maior nas doses de 8 e $10 \mathrm{~g}$. O tamanho das folhas dessas brotações e das folhas novas do ápice era reduzido, a cor, amarela e as bordas, de algumas delas, estavam necrosadas.

Aos 135 DAA, em todas as doses, observou-se a ocorrência de frutos nas fases de maturação e de deiscência. Nas plantas tratadas com 2, 4 e $6 \mathrm{~g}$ o sintoma das folhas mais velhas não evoluiu. No entanto, as folhas mais novas, que estavam normais na avaliação anterior, apresentavam-se amareladas. Nas plantas tratadas com 8,10 e $20 \mathrm{~g}$, os sinto mas das brotações e folhas novas, continuavam como descritos na av al iação an te ri or. Visualmente, as plantas tratadas com as doses de 2 a $6 \mathrm{~g}$ estavam semelhantes às tratadas com as doses de $8 \mathrm{a} 20 \mathrm{~g}$.

Aos 186 DAA, plantas de todos os doses tratamentos encontravam-se totalmente desfolhadas. Houve deiscência das sementes, queda dos resíduos dos frutos e queda das brot ações. To das as plantas ap re sentavam brotações novas amareladas, na base dos caules

primári os e secund ários, até a uma altura aproximada de 1,0 $\mathrm{m}$ do solo. Em todas as doses, no ápice de algumas plantas foram observadas brotações novas, todas amareladas e algumas com os bordos foliares necrosados. No aspecto geral, todas as doses foram semelhantes entre si.

Aos 240 DAA, as brotações basais de to das as plantas, em todas as doses, haviam morrido e caído. Nesta data, o número de plantas com brotações novas variou de uma dose para outra (Figura 7). Essas brotações apresentavam-se amareladas e ocorriam ao longo dos caules, exceto na base, próximo ao solo.

As avaliações realizadas aos 50, 93, 135, 186 e 240 dias após a aplicação de tebuthiuron comprovam o mecanismo de ação desse herbicida que, segundo Rodrigues \& Almeida (1995), inibe a fotossíntese, provocando a clorose e necrose foliar nas espécies anuais e, nos arbustos, provoca abscisão foliar, ao que a planta reage com emissão de nova folhagem. Nesse processo, de acordo com os autores, esgotam-se as reservas nutritivas, provocando a morte das plantas, após um período de três meses a mais de um ano.

Na úl ti ma aval iação, ao s 271 DAA, nenhuma planta apresentou brotações. Os ramos apresentavam-se secos e fáce is de quebrar até à base do tronco. Nessa data, todas as plantas, em todas as doses, estavam mortas. 


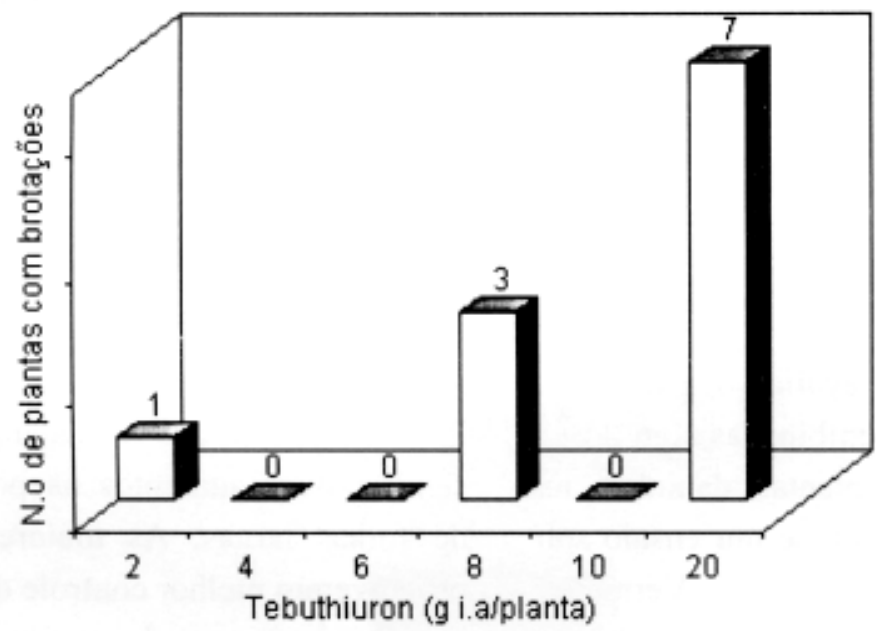

FIGURA 7. Número de plantas com brotações (do total de 10 plantas), aos 240 dias após a aplicação de tebuthiuron. Ibiporã, 1995.

\section{AGRADECIMENTOS}

Os autores expressam

seus agradecimentos à Inês Fumiko Ubukata Yada, Técnica da Biometria do IAPAR.

\section{LITERATURA CITADA}

BLOSSFELD, H. Jardinagem. São

Melhoramentos, 1965. 418p.

HOLM, L., PANCHO, J.V., HERBERGER, J.P., PLUNKENET, D.L. A geographical atlas of world weeds. JOHN WILEY \& SONS, 1979.391p.

KR ANZ, W.M., PASSINI, T. Tecoma stans (L.)Kunth (Bignonaceae), planta invasora de pastagens no Estado do Paraná. In: CONGRESSO NACIONAL DE
BOTÂNICA, 47, No va Friburgo -RJ, 1996. Resumos... p.315.

MORTON, J.F. Atlas of medicinal plants of Middle American; Bahamas to Yucatan. Charles C. Thomas, Springfield-USA, 1981.1420p.

Paulo, OAKES, A.J. Herbicidal control of Tecoma stans (L.) Juss. ex HBK. Turrialba, v.20, n.4, p.415-418, 1970.

RODR IGUES, B.N., ALMEIDA, F.S. de. Guia de Herbicidas. 3 ed. Londrina, 1995. $675 \mathrm{p}$.

SANDWITH, N.Y., HUNT, D.R. Bignoniáceas. Itajaí, CNP/IBDF/Herbário "Barbosa Ro drigu es ", 1974. (Flor a Il us trad a Catarinense. Parte I: As plantas. Fascículo: Bignoniácias). p.62-64. 